\title{
Substrate-fungus interaction on the enzymatic and non-enzymatic antioxidant activities of solid state fermentation system
}

\author{
Taha Mohamed El-Katony * (1), Mahmoud Metwally Nour El-Dein, Amira Ali El-Fallal, Nourhan Gamal Ibrahim \\ and Mohamed Mohamed Mousa
}

\begin{abstract}
The fungus-substrate interaction on the antioxidant activity of a solid state fermentation system (SSFS) was investigated employing two basidiomycete fungi: Pleurotus columbinus and P. floridanus and two ascomycetes: Aspergillus fumigatus and Paecilomyces variotii on powdered peels of banana, pomegranate and orange, empty pea pods and rice straw. The oven-dried substrates were moistened at $90 \%$ water holding capacity, inoculated with the test fungi and incubated at $25^{\circ} \mathrm{C}$ for appropriate time. Culture extracts were tested for the enzymatic and non-enzymatic antioxidant activity. The effect of substrate on the antioxidant activity of the SSFS was stronger than that of the fungal species. Peroxidase (POX) activity was higher in the basidiomycetes than ascomycetes and achieved its maximum in $P$. floridanus versus complete absence in A. fumigatus. By contrast, catalase (CAT) activity was higher in the ascomycetes, particularly P. variotii on banana peel, than in the basidiomycetes. Phenolics and flavonoids were highest in pomegranate peels but lowest in banana peels and rice straw, and they were subjected to severe consumption by the basidiomycetes versus mild production by the ascomycetes. The reducing power (RP) and DPPH scavenging activity were higher in the peels of pomegranate, orange and banana relative to rice straw and empty pea pods, and the fungal effect was limited and independent of the fungal taxonomic group. Orange peel is the appropriate substrate for production of fungal CAT and POX, which activities were mutually exclusive; but pomegranate peel is more suitable for production of phenolics and flavonoids.
\end{abstract}

Keywords: Antioxidants, Ascomycetes, Basidiomycetes, Fruit peels, Rice straw, Solid state fermentation

\section{Introduction}

Harvesting and processing of fruits and vegetables generate huge quantities of organic wastes, most of which is being disposed in the landfills and rivers, causing serious environmental problems. In Egypt, agricultural wastes approached 33 million tons a year, of which only $30 \%$ are utilized in profitable practices and the remainder is usually discarded by incineration which leads to loss

\footnotetext{
*Correspondence: tmsoliman2000@yahoo.co.uk Department of Botany and Microbiology, Faculty of Science, Damietta University, New Damietta 34517, Egypt
}

of value-added products and environmental pollution (Abou Hussein and Sawan 2010). The nonedible portion of fruits and vegetables such as peels, pods, seeds, skins, etc. accounts for $10-60 \%$ of the total weight of the fresh produce, with high content of organic matter, phytochemicals, and nutraceutical compounds that may concentrate up to several folds their concentration in the edible fraction (Wadhwa et al. 2015). Therefore, these residues might represent a considerable loss of valuable resources if not properly managed (Sharma et al. 2016). Fortunately, such organic wastes can find many uses; for example, in animal nutrition and fermentation 
(Ravindran and Jaiswal 2016) as well as the production of value-added phytochemicals such as bio-pigments; oils rich in polyunsaturated fatty acids, organic acids, single-cell protein, essential oils, enzymes, bio-ethanol, bio-pesticides, bio-sorbents, bio-degradable plastic, bio-fertilizers, bio-preservatives and edible mushrooms (Martinez-Avila et al. 2014; Wadhwa et al. 2015).

Utilization of organic wastes in the production of biofuel is a growing concern, and rice straw is particularly promising in this concern because it can be readily converted to ethanol by fermentation with fungi (Singh et al. 2016). It is estimated that about 3.1 million tons of rice straw are disposed annually in Egypt, which can, if properly manipulated, generate about $2447 \mathrm{GWh}$ /year (Abdelhady et al. 2014). In addition, rice straw can be used as a fodder after amendment with urea or ammonia to increase its protein content and can also be used as a substrate for cultivation of mushrooms and vegetable crops in salt-affected lands (Abou Hussein and Sawan 2010). In addition to rice straw, there are a range of valuable plant wastes rich in nutraceuticals such as banana peels and foliage, citrus peels and pulps, sun-dried ground pomace, cauliflower and cabbage residues, straw and empty pods of pea and cull potatoes. These wastes can be used as fodder or as organic fertilizers and soil conditioners either in the native form or after some processing, e.g., composting and ensiling with broiler litter and rice and wheat straw (Brar et al. 2013).

The human body requires regular intake of natural antioxidants of plant/microbial origin to avoid the dangerous consequences of the oxidative stress arising from the improper life style and consumption of junk foods enriched with synthetic flavorings and preservatives (Carocho et al. 2018). The proper manipulation of the agro-industrial wastes represents a valuable source of natural antioxidants and bioactive compounds, particularly the polyphenols. Polyphenols exhibit anti-cancer, anti-microbial, anti-oxidative and immune-stimulating effects, and can reduce the incidence of cardiovascular diseases, atherosclerosis, diabetes and rheumatoid arthritis (Wadhwa et al. 2015; Ranneh et al. 2017). In the food industry, after processing of fruits and vegetables, their solid wastes (seeds, peels, or whole pomace) contain soluble sugars, fibers, minerals and vitamins, along with low-lignin content. These unique composition evaluates these wastes to host a wide range of beneficial microorganisms and can be metabolized into value-added bioactive products such as antioxidants, antibiotics as well as enzymatic preparations (Biswas and Biswas 2015; Sharma et al. 2016).

Fermentation of plant residues with the appropriate microbes, manipulating the solid state fermentation system (SSFS), represents an environmentally safe and efficient technology for production of a wide array of bioactive compounds in the food and pharmaceutical industries. Many enzymes, bioactive metabolites as well as antibiotics have been successfully produced employing the SSFS technique (Bind et al. 2014; Inácio et al. 2015; Schmidt et al. 2014). Fermentation of seeds and flour of rice may be a good source of natural antioxidants compared to non-fermented rice (Sadh et al. 2017). Fermentation of soybean with Bacillus subtilis improved its overall nutritional content and antioxidant activity, which could serve as a potential low-cost animal feed or a constituent of human diet (Mok et al. 2019). Fungi by themselves, particularly the mushrooms, can profoundly participate in the production of secondary metabolites and antioxidants including phenolics, flavonoids, $\beta$-glucans and steroids (Butkhup et al. 2018).

Therefore, the choice of the appropriate fungal species and plant wastes in an SSFS will maximize the production of antioxidants. For example, by manipulating an SSFS with different basidiomycete and ascomycete fungi on orange peel, El-Katony et al. (2019) demonstrated a profound differential antioxidant activity depending on the fungal taxonomic group. The present work investigates the antioxidant activity of an SSFS consisting of two basidiomycete fungi: Pleurotus columbinus and $P$. floridanus and two ascomycetes: Aspergillus fumigatus and Paecilomyces variotii on five common agro-residues in Egypt viz. peels of banana, pomegranate and orange, empty pea pods, and rice straw. We aim to find out the most efficient fungus-substrate combination in production of both enzymatic and non-enzymatic antioxidants, in a way to switch the accumulation of the problematic agro-residues into value-added products.

\section{Materials and methods}

\section{Fungal species and substrates}

Four fungal species were used in this study: the two basidiomycetes Pleurotus columbinus (Quel. Ap. Bres) and Pleurotus floridanus Sing $(38,539)$ and the two ascomycetes Aspergillus fumigatus (Fresenius) and Paecilomyces variotii (Biourge \& Bainier). Collection, identification and maintenance of the fungal species have been detailed in El-Katony et al. (2019). The agro-residues used (peels of banana, pomegranate and orange, empty pea pods, and rice straw) were obtained from the local market at the ripe stage. Residues were washed twice with distilled water, left to dry in the shade and dried in a hot air oven at $50 \pm 5{ }^{\circ} \mathrm{C}$. Since banana is a climacteric fruit, the chemical composition and the biological value of the peel are expected to vary with the ripening stage of the fruit ( Vu et al. 2018). Therefore, banana peel was used at the golden-yellow stage of ripening. The dried residues were grinded into fine powder, passed through 1-mm 
mesh and kept in air-tight containers until used in solid state fermentation.

\section{Chemicals and equipment}

The chemicals used in this study were 1, 1-diphenyl2-picrylhydrazyl (DPPH) obtained from Sigma-Aldrich, USA; 2,4-dichlorophenol (2,4-DCP), 4-aminoantipyrine, Folin-Ciocalteu phenol reagent, gallic acid, quercetin and trichloroacetic acid obtained from Fisher Scientific, UK. All other reagents and solvents used were of analytical grade. The equipment used were laboratory triple-walled vertical autoclave, Russia; WIS-10 bench top shaker incubator, Korea; 3H24RI Intelligent high-speed refrigerated centrifuge, Herexi Instrument \& Equipment Company, China; S/N M0017053 Microcentrifuge, Denver Instrument Company, USA and V-630 UV/VIS/NIR Spectrophotometer, Jasco Company, Japan.

\section{Solid state fermentation}

The antioxidant activity of the SSFS was investigated by growing the four fungal species on the experimental powdered agro-residues in 250-ml Erlenmeyer flasks. Water was added to the powdered residues at $90 \%(\mathrm{w} / \mathrm{w})$ of the water-holding capacity of the substrates and the flasks were autoclaved at $120^{\circ} \mathrm{C}$ for $15 \mathrm{~min}$. The substrates were inoculated with two disks, each of $2 \mathrm{~cm}$ diameter from an established culture of the test fungi on PDA medium. The cultures were incubated at $25 \pm 2{ }^{\circ} \mathrm{C}$ for 14 days for the basidiomycete fungi and 7 days for the ascomycete fungi.

\section{Extraction of enzymes and non-enzymatic antioxidants}

For enzyme extraction, the whole culture was mixed thoroughly with $50 \mathrm{ml}$ of phosphate buffer $(0.1 \mathrm{M}, \mathrm{pH}$ 7.0) and the mixture was incubated in a rotary shaker at $180 \mathrm{rpm}$ and $30{ }^{\circ} \mathrm{C}$ for $2 \mathrm{~h}$. The mixture was then filtered through a wet muslin cloth, followed by centrifugation at $10,000 \times g$ for $15 \mathrm{~min}$ at $4{ }^{\circ} \mathrm{C}$ and the clear supernatant was used for enzyme assay. For estimation of nonenzymatic antioxidants, $50 \mathrm{ml}$ of $95 \%$ ethanol was added to the culture, and the mixture was incubated for $2 \mathrm{~h}$ at room temperature in the rotary shaker at $250 \mathrm{rpm}$. The mixture was then filtered through wet muslin cloth and the filtrate was centrifuged at $2800 \times g$ for $10 \mathrm{~min}$ at room temperature and the clear supernatant was used for assay of phenolics, flavonoids, RP and DPPH scavenging activity of the SSFS.

\section{Assay of peroxidase activity}

Peroxidase (POX, EC 1.11.1.x) activity was assayed according to the method described by Ramachandra et al. (1988), using 2,4-dichlorophenol (2,4-DCP) as the substrate. The final reaction mixture $(3 \mathrm{ml})$ contained $0.6 \mathrm{ml}$ of potassium phosphate buffer $(0.1 \mathrm{M}, \mathrm{pH} 7.0)$,
$0.6 \mathrm{ml}$ of $16 \mathrm{mM} 4$-aminoantipyrine, $0.6 \mathrm{ml}$ of $25 \mathrm{mM}$ 2,4-DCP and $0.6 \mathrm{ml}$ of the culture supernatant. The reaction was initiated by the addition of $0.6 \mathrm{ml}$ of $50 \mathrm{mM}$ $\mathrm{H}_{2} \mathrm{O}_{2}$. The mixture was then incubated at $50^{\circ} \mathrm{C}$ for $1 \mathrm{~min}$. The increase in absorbance as a result of the oxidation of 4-aminoantipyrine was measured at $510 \mathrm{~nm}$. One unit of enzyme activity was defined as the amount of enzyme required to increase absorbance by one unit $\mathrm{ml}^{-1}$.

\section{Assay of catalase activity}

Catalase (CAT, EC 1.11.1.6) activity was assayed according to the procedure described by Teranishi et al. (1974). An aliquot of $0.1 \mathrm{ml}$ the culture supernatant was added to $1 \mathrm{ml}$ of $2 \mathrm{mM} \mathrm{H}_{2} \mathrm{O}_{2}$ and $1.9 \mathrm{ml}$ of the phosphate buffer $(0.1 \mathrm{M}, \mathrm{pH} 7.5)$. The mixture was incubated at $30{ }^{\circ} \mathrm{C}$ for $5 \mathrm{~min}$, then $4 \mathrm{ml}$ of the titanium reagent was added to stop the reaction and the mixture was centrifuged at $3000 \times g$ for $10 \mathrm{~min}$. Absorbance was measured at $415 \mathrm{~nm}$. The residual $\mathrm{H}_{2} \mathrm{O}_{2}$ of the sample was calculated by reference to a standard curve in the range of $0-200$ $\mu$ mole $\mathrm{H}_{2} \mathrm{O}_{2}$. Enzyme activity was expressed as $\mu$ mole $\mathrm{H}_{2} \mathrm{O}_{2} \mathrm{ml}^{-1}$. Titanium reagent was prepared by dissolving $1 \mathrm{~g}$ of titanium oxide and $10 \mathrm{~g}$ of $\mathrm{K}_{2} \mathrm{SO}_{4}$ in $150 \mathrm{ml}$ of conc. $\mathrm{H}_{2} \mathrm{SO}_{4}$ with heating for $2-3 \mathrm{~h}$ on a hot plate; the mixture was cooled and made up to $1.5 \mathrm{~L}$ with water.

\section{Assay of total phenolics}

The total phenolics content of the culture was assayed according to the method described by Luque-Rodríguez et al. (2007). An aliquot of $0.4 \mathrm{ml}$ of the ethanolic extract was added to a mixture of $2 \mathrm{ml}$ of $0.25 \mathrm{~N}$ Folin-Ciocalteu phenol reagent and $1.6 \mathrm{ml}$ of $7.5 \% \mathrm{Na}_{2} \mathrm{CO}_{3}$. The mixture was heated in water bath at $50{ }^{\circ} \mathrm{C}$ for $5 \mathrm{~min}$, cooled to room temperature in darkness and the absorbance was read at $760 \mathrm{~nm}$. The content of total phenolics was estimated with reference to a standard curve using gallic acid in the range of $0-100 \mu \mathrm{g} \mathrm{ml}^{-1}$; and the concentration was expressed as $\mu$ g gallic acid equivalent $\mathrm{ml}^{-1}$.

\section{Assay of total flavonoids}

The total flavonoids' content of the culture was assayed according to the method described by Yang et al. (2009). An aliquot of $0.25 \mathrm{ml}$ of the ethanolic extract was mixed with $1.25 \mathrm{ml}$ of distilled water and $75 \mu \mathrm{l}$ of $5 \% \mathrm{NaNO}_{2}$. After $6 \mathrm{~min}, 150 \mu \mathrm{l}$ of $10 \% \mathrm{AlCl}_{3}$ was added and the mixture was left for $5 \mathrm{~min}$ prior to addition of $0.5 \mathrm{ml}$ of $1 \mathrm{M}$ $\mathrm{NaOH}$ and $775 \mu \mathrm{l}$ of distilled water. Absorbance was measured at $510 \mathrm{~nm}$. The content of total flavonoids was estimated with reference to a standard curve of quercetin in the range of $0-500 \mu \mathrm{g} \mathrm{ml}^{-1}$; and the concentration was expressed as $\mu \mathrm{g}$ quercetin equivalent $\mathrm{ml}^{-1}$. 


\section{Estimation of the reducing power (RP)}

The reduction potential of the culture was estimated according to the method of Oyaizu (1986). An aliquot of $1 \mathrm{ml}$ of the ethanolic extract was mixed with $2.5 \mathrm{ml}$ of phosphate buffer $(0.2 \mathrm{M}, \mathrm{pH} 6.6)$ and $2.5 \mathrm{ml}$ of $1 \%$ $\mathrm{K}_{3} \mathrm{Fe}(\mathrm{CN})_{6}$. The mixture was incubated at $50{ }^{\circ} \mathrm{C}$ for $20 \mathrm{~min}$, and $2.5 \mathrm{ml}$ of $10 \%$ trichloroacetic acid was added. The mixture was centrifuged for $10 \mathrm{~min}$ at $1000 \times g$. An aliquot $(2.5 \mathrm{ml})$ of the supernatant was mixed with $2.5 \mathrm{ml}$ of distilled water and $0.5 \mathrm{ml}$ of $0.1 \% \mathrm{FeCl}_{3}$. The absorbance was measured at $700 \mathrm{~nm}$. High absorbance of the reaction mixture indicates great RP.

\section{DPPH scavenging activity}

The capacity of the SSFS to scavenge the stable free radical 2,2-diphenyl-1-picrylhydrazyl (DPPH) was monitored according to the method of Hatano et al. (1988). An aliquot $(0.3 \mathrm{ml})$ of the ethanolic extract was mixed with $2.7 \mathrm{ml}$ of DPPH solution $\left(6 \times 10^{-5} \mathrm{~mol} \mathrm{l}^{-1}\right)$. The mixture was shaken vigorously and left to stand for $60 \mathrm{~min}$ in the dark to attain stable absorbance. The reduction of the DPPH radical was measured by monitoring the decrease in absorbance at $517 \mathrm{~nm}$. The DPPH scavenging activity was calculated as a percentage of DPPH discoloration using the equation:

$$
\text { DPPH scavenging activity }=\frac{\left(A_{\mathrm{d}}-A_{\mathrm{c}}\right)}{A_{\mathrm{d}}} \times 100
$$

where $A_{\mathrm{c}}$ is the absorbance of the sample and $A_{\mathrm{d}}$ the absorbance of the DPPH solution.

\section{Statistical analysis}

The experiment was factorial with two factors and three replicates in a completely randomized design. The two factors were (1) type of substrate with five levels: peels of banana, pomegranate and orange, empty pea pods, rice straw and orange peel; and (2) species of fungi with five levels: the four fungal species in addition to the noninoculated control. Data were subjected to two-way ANOVA using the SPSS program, version 22. Since the DPPH scavenging activity was expressed as percentage, the data were arcsine-transformed before performing ANOVA. Likewise, because of the wide variability in the magnitudes of phenolics' and flavonoids' contents among the different treatments, their data were log-transformed before performing ANOVA. ANOVA and mean separation (using the Duncans' multiple range test) were applied to the transformed data to ensure homogeneity of variance.

\section{Results}

The effects of the main factors (type of substrate and fungal species) and their interaction on the enzymatic and non-enzymatic antioxidant activities of the SSFS were very highly significant $(P<0.001)$, with stronger effect of substrate (greater $\mathrm{F}$ ratio) than the fungal species, except with CAT where the reverse was true (Table 1). POX activity of the SSF system was higher in the basidiomycete fungi, particularly on orange peel, than in the ascomycetes. In addition, POX activity was not detected in all the tested fungi on pomegranate peel, in the two ascomycetes on orange peel and in A. fumigatus on all substrates (Table 2). By contrast, CAT activity was markedly high in the ascomycete fungi versus a general very low activity in the basidiomycetes which exhibited no enzyme activity on rice straw, pomegranate peels and empty pea pods (Table 2).

Table 1 Two-way ANOVA showing the effect of the main factors (type of substrate and fungus) and their interaction on the antioxidant activity of the SSFS

\begin{tabular}{|c|c|c|c|c|c|c|c|}
\hline $\begin{array}{l}\text { Variable and source } \\
\text { of variation }\end{array}$ & $d f$ & $F$ & $P$ & $\begin{array}{l}\text { Variable and source } \\
\text { of variation }\end{array}$ & $d f$ & $F$ & $P$ \\
\hline Peroxidase & & & & Flavonoids & & & \\
\hline Substrate & 4 & 21,627 & 0.000 & Substrate & 4 & 17,630 & 0.000 \\
\hline Fungus & 4 & 14,722 & 0.000 & Fungus & 4 & 979 & 0.000 \\
\hline Substrate $\times$ fungus & 16 & 10,035 & 0.000 & Substrate $\times$ fungus & 16 & 350 & 0.000 \\
\hline Catalase & & & & Reducing power (RP) & & & \\
\hline Substrate & 4 & 7270 & 0.000 & Substrate & 4 & 412.9 & 0.000 \\
\hline Fungus & 4 & 24,459 & 0.000 & Fungus & 4 & 2.934 & 0.030 \\
\hline Substrate $\times$ fungus & 16 & 2467 & 0.000 & Substrate $\times$ fungus & 16 & 3.129 & 0.001 \\
\hline Phenolics & & & & DPPH scavenging acti & & & \\
\hline Substrate & 4 & 14,453 & 0.000 & Substrate & 4 & 336,933 & 0.000 \\
\hline Fungus & 4 & 2194 & 0.000 & Fungus & 4 & 26,608 & 0.000 \\
\hline Substrate $\times$ fungus & 16 & 643 & 0.000 & Substrate $\times$ fungus & 16 & 25,165 & 0.000 \\
\hline
\end{tabular}


Table 2 The activity of POX and CAT in an SSFS employing two basidiomycete fungi: $P$. columbinus and $P$. floridanus and two ascomycetes: $A$. fumigatus and $P$. variotii on peels of banana, pomegranate and orange, empty pods of pea, and rice straw

\begin{tabular}{|c|c|c|}
\hline Substrate and fungus & $\begin{array}{l}\text { Peroxidase } \\
\text { activity }\left(\mathrm{U} \mathrm{ml}^{-1}\right)\end{array}$ & $\begin{array}{l}\text { Catalase activity } \\
\left(\mu \mathrm{mol} \mathrm{H}_{2} \mathrm{O}_{2}\right. \\
\left.\mathrm{ml}^{-1}\right)\end{array}$ \\
\hline \multicolumn{3}{|l|}{ Banana peel } \\
\hline P. columbinus & $0.098 \pm 0.003^{e}$ & $2.834 \pm 0.027^{d}$ \\
\hline P. floridanus & $0.063 \pm 0.002^{c}$ & $3.412 \pm 0.014^{f}$ \\
\hline A. fumigatus & ND & $16.91 \pm 0.009^{\mathrm{kl}}$ \\
\hline P. variotii & $0.060 \pm 0.005^{c}$ & $18.53 \pm 0.009^{m}$ \\
\hline \multicolumn{3}{|l|}{ Pomegranate peel } \\
\hline P. columbinus & ND & ND \\
\hline P. floridanus & ND & ND \\
\hline A. fumigatus & ND & $2.08 \pm 0.041^{b}$ \\
\hline P. variotii & ND & $2.94 \pm 0.169^{\text {de }}$ \\
\hline \multicolumn{3}{|l|}{ Empty pea pods } \\
\hline P. columbinus & $0.078 \pm 0.002^{d}$ & ND \\
\hline P. floridanus & $0.052 \pm 0.000^{b c}$ & ND \\
\hline A. fumigatus & ND & $10.81 \pm 0.018^{i}$ \\
\hline P. variotii & $0.042 \pm 0.001^{b}$ & $16.85 \pm 0.074^{k}$ \\
\hline \multicolumn{3}{|l|}{ Orange peel } \\
\hline P. columbinus & $1.15 \pm 0.013^{h}$ & $2.46 \pm 0.287^{c}$ \\
\hline P. floridanus & $2.29 \pm 0.017^{i}$ & ND \\
\hline A. fumigatus & ND & $6.88 \pm 0.115^{\mathrm{g}}$ \\
\hline P. variotii & ND & $7.97 \pm 0.057^{h}$ \\
\hline \multicolumn{3}{|l|}{ Rice straw } \\
\hline P. columbinus & $0.178 \pm 0.000^{f}$ & ND \\
\hline P. floridanus & $0.273 \pm 0.000^{g}$ & ND \\
\hline A. fumigatus & ND & $0.319 \pm 0.000^{a}$ \\
\hline P. variotii & $0.028 \pm 0.000^{a}$ & $12.96 \pm 0.000^{j}$ \\
\hline
\end{tabular}

Each value is the mean of three replicates \pm SE. Means with common letters are not significantly different at $P<0.05$

ND not detected

The phenolics' content of the native pomegranate and orange peels and empty pea pods was twice its level in rice straw and banana peel (Fig. 1). The phenolics' content of the SSFS was differentially affected by the action of test fungi. In general, the basidiomycete fungi exhibited marked consumption of the substrate phenolics versus mild production or no effect by the ascomycete fungi. This differential effect was most evident on rice straw but very weak on pomegranate and orange peels (Fig. 1). The phenolics-consuming activity was comparable in the two basidiomycetes, with an average of $75 \%, 33 \%$ and $1 \%$ on rice straw, banana peel and pomegranate peel, respectively; but it was in favor of $P$. floridanus on empty pea pods and $P$. columbinus on orange peel. Despite of the overall mild effect of the ascomycete fungi on phenolics' content of the different substrates, A. fumigatus exerted a pronounced effect, manifested as $57 \%$ increase on rice straw versus $24 \%$ decrease on banana peel.

The variability in flavonoids' content among the native substrates was drastic compared with that in phenolics, being 30 times higher in pomegranate peel above orange peel. The fungal action on substrate flavonoids followed a pattern similar to that of phenolics (Fig. 2). The flavonoid-consuming activity of the basidiomycetes was most aggressive on rice straw, with almost complete depletion of the substrate flavonoids. By contrast, the consuming ability was moderate or mild and amounted to $34 \%$ and $8 \%$ of the substrate flavonoids by $P$. floridanus and $P$. columbinus, respectively, on banana and pomegranate peels and empty pea pods. The action of the two ascomycete fungi on substrate flavonoids was marginal in rice straw, banana peel and pomegranate peel. By contrast, the action of the two fungi on the flavonoid content of the remaining substrates was marked and differed from $43 \%$ consumption in empty pea pods to tenfold increase in orange peel (Fig. 2).

The RP of the native substrates was lowest in rice straw, intermediate in empty pea pods, banana peel and orange peel but highest in pomegranate peel. The fungal effect on the RP of the substrate was generally independent of the fungal taxonomic group and was relatively mild on peels of banana, pomegranate and orange (Fig. 3). The RP of empty pea pods was reduced by an average of $22 \%$ due to the basidiomycete $P$. columbinus and the ascomycete A. fumigatus and by an average of $55 \%$ due to $P$. floridanus and $P$. variotii. The fungal action on the reducing power of rice straw varied from doubling the native content by $P$. columbinus, through a mild effect of $P$. variotii and $A$. fumigatus to $60 \%$ reduction by $P$. floridanus (Fig. 3).

The DPPH scavenging activity of the native substrates was high in the peels of banana, orange and pomegranate, intermediate in rice straw and negligible in empty pea pods (Fig. 4). The effect of fungi on the DPPH scavenging activity was generally mild on the three active substrates (peels of banana, orange and pomegranate). On rice straw, the ascomycete fungi appreciably increased DPPH scavenging activity, particularly $P$. variotii which led to $230 \%$ increase, versus $60 \%$ reduction due to the two basidiomycetes. The fungal action raised the negligibly low DPPH scavenging activity of empty pea pods to levels slightly lower or comparable to that of rice straw, with apparent magnification of the positive effect of the fungal action (Fig. 4). 


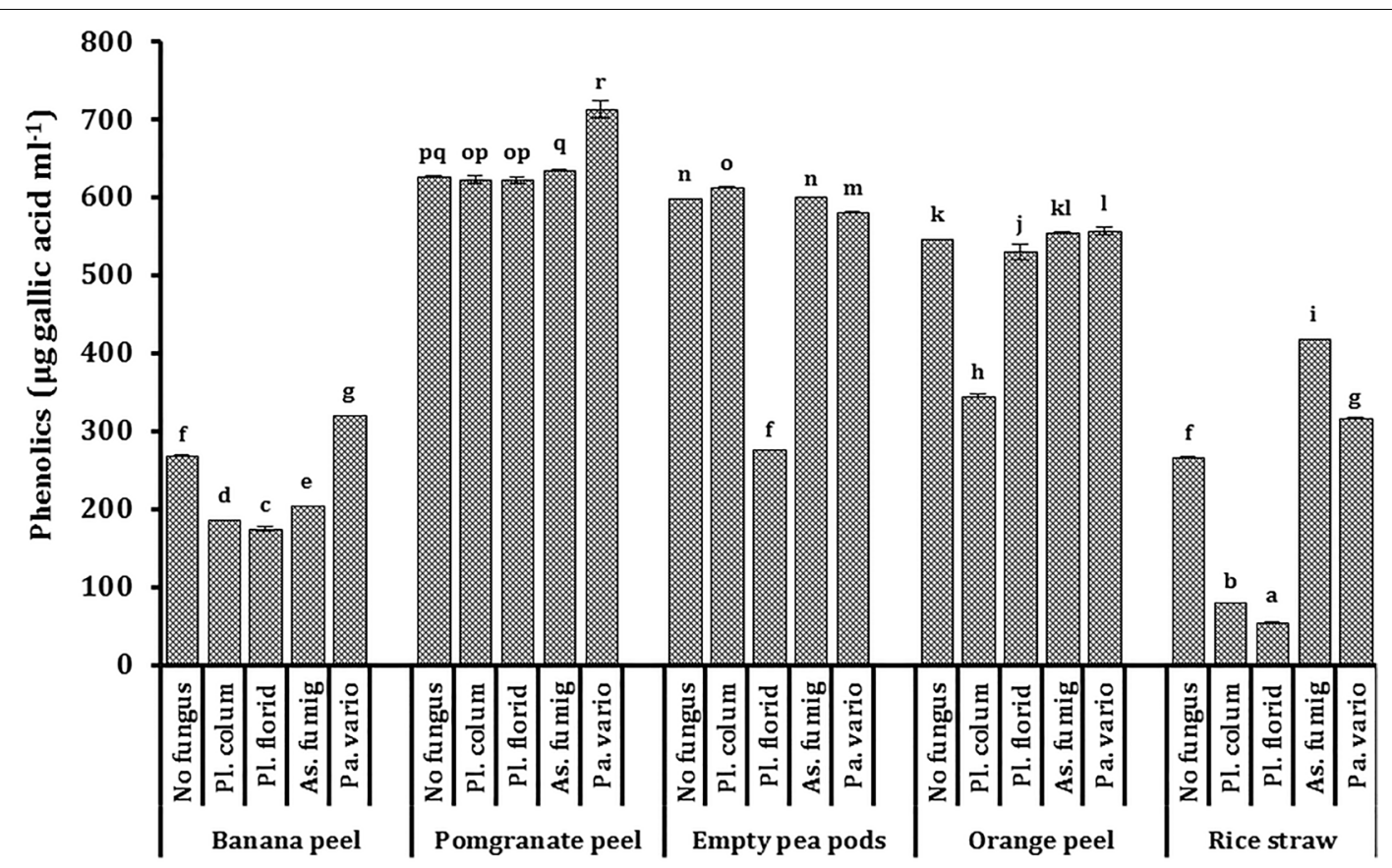

Substrate and fungus

Fig. 1 Phenolic content of an SSFS employing two basidiomycete fungi: P. columbinus and P. floridanus and two ascomycetes: A. fumigatus and P. variotii on peels of banana, pomegranate and orange, empty pods of pea and rice straw. Each column represents the mean of three replicates $\pm S E$. Columns with common letters are not significantly different at $P<0.05$

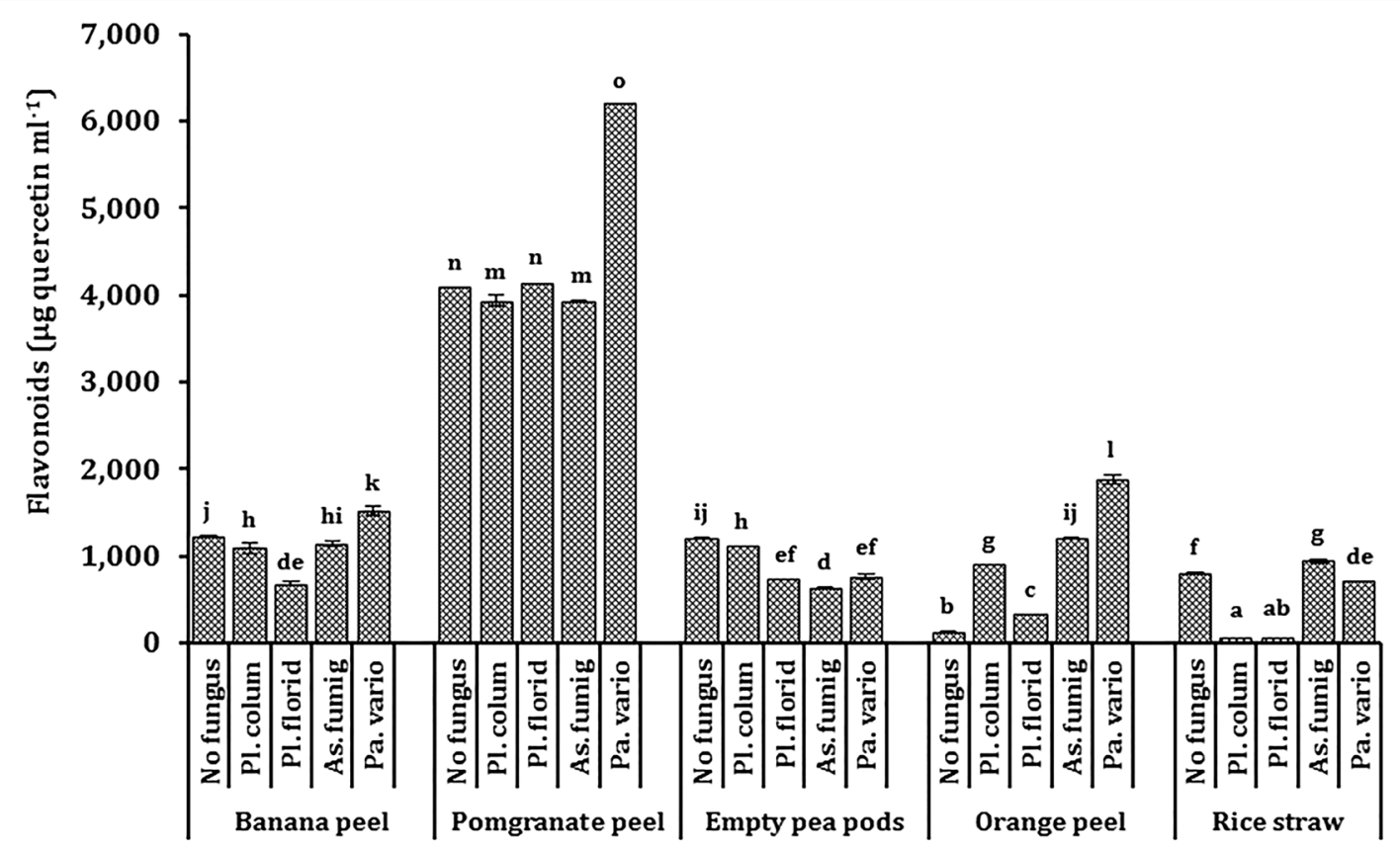

\section{Substrate and fungus}

Fig. 2 Flavonoid content of an SSFS employing two basidiomycete fungi: P. columbinus and $P$. floridanus and two ascomycetes: A. fumigatus and $P$. variotii on peels of banana, pomegranate and orange, empty pods of pea and rice straw. Each column represents the mean of three replicates $\pm \mathrm{SE}$. Columns with common letters are not significantly different at $P<0.05$ 


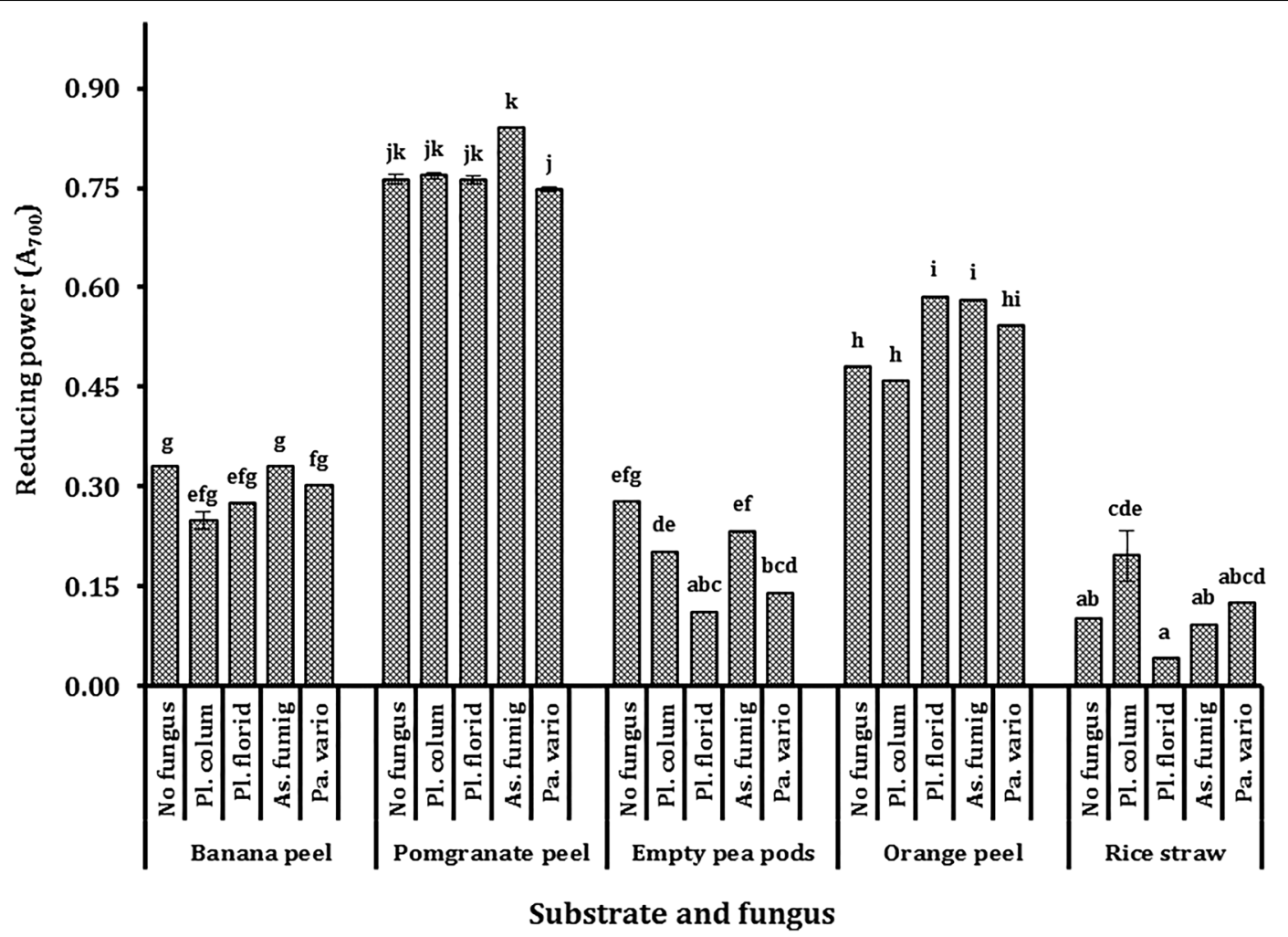

Fig. 3 Reducing power of an SSFS employing two basidiomycete fungi: P. columbinus and PI. floridanus and two ascomycetes: A. fumigatus and P. variotii on peels of banana, pomegranate and orange, empty pods of pea and rice straw. Each column represents the mean of three replicates \pm SE. Columns with common letters are not significantly different at $P<0.05$

\section{Discussion}

Although the role of fungi in the antioxidant activity of SSF systems has been appreciated (Sadh et al. 2017), the present findings suggest that for constructing an SSFS the choice of the substrate is more important than the choice of fungal species. The complete absence of POX activity by the four tested fungi and of CAT by the two basidiomycetes, along with the low CAT activity by the two ascomycetes, on pomegranate peel suggests that this agro-residue is not the proper substrate for the production of fungal CAT and POX. Rather, it seems more suitable for the production of the non-enzymatic antioxidants, namely phenolics and flavonoids. By contrast, orange peel seems more appropriate for the production of both fungal POX and CAT while banana peel is more suitable for CAT. While the basidiomycete fungi possess higher POX activity compared with the ascomycetes, the reverse was true for CAT. It seems also that the two enzymes are mutually exclusive since high POX activity was associated with low CAT activity and vice versa (Fig. 5a). In agreement with the present findings, El-Katony et al. (2019), using different basidiomycetes and ascomycetes on orange peel as a substrate, demonstrated POX activity only by the basidiomycete fungi, particularly $P$. columbinus versus a favorite activity of CAT by the ascomycetes, particularly $P$. variotii and $A$. fumigatus.

The lower phenolic content of banana peel and rice straw relative to pomegranate and orange peels is in agreement with the findings of Babbar et al. (2011) that, among several plant residues, banana peel exhibited low phenolic content with low antioxidant activity. Rather, pomegranate peel has been reported to contain high contents of phenolics and flavonoids, with predominance of gallic, chlorogenic and caffeic acids (Souleman and Ibrahim 2016). The phenolic content of the tested substrates was subjected to substantial fungal influence, which is related to the taxonomic group of the fungus. It seems that growth of the basidiomycete fungi was associated with consumption of the substrate phenolics versus mild production or no effect by the ascomycete fungi. This pattern was, however, more evident in the low-phenolic substrate (rice straw) than in the high-phenolic substrates (peels of pomegranate and orange). The potentiality of basidiomycete fungi for consumption of orange peel phenolics versus the producing ability of the ascomycetes has been demonstrated by El-Katony et al. (2019). 


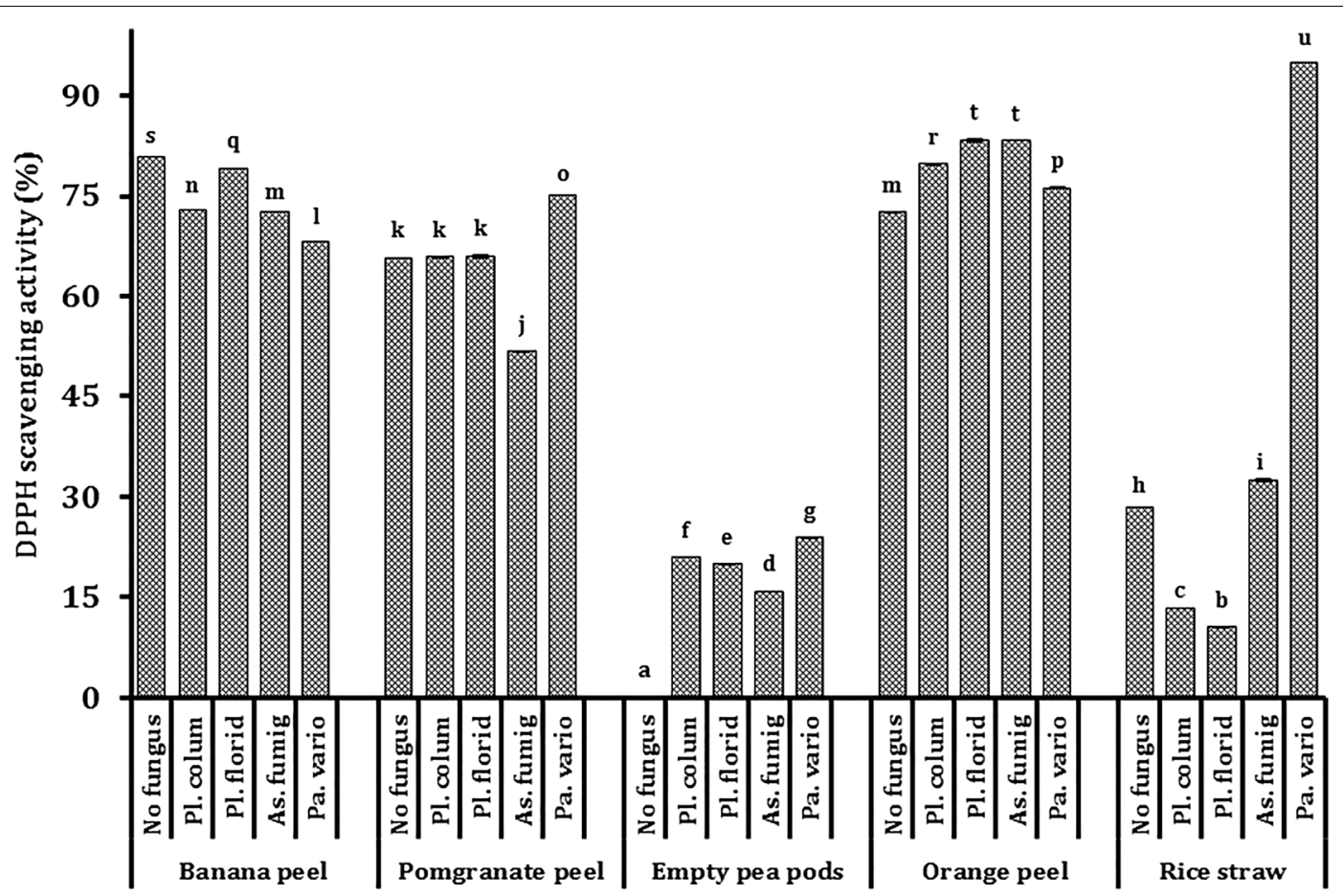

Substrate and fungus

Fig. 4 DPPH scavenging activity of an SSFS employing two basidiomycete fungi: P. columbinus and P. floridanus and two ascomycetes: A. fumigatus and $P$. variotii on peels of banana, pomegranate and orange, empty pods of pea and rice straw. Each column represents the mean of three replicates \pm SE. Columns with common letters are not significantly different at $P<0.05$

In addition, growth of the ascomycete Trichoderma harzianum on soybean increased the contents of phenolics and flavonoids of the SSFS, and this was associated with greater antioxidant activity and significant protection against oxidative DNA and protein damage caused by hydroxyl radicals (Singh et al. 2010).

The present findings reveal significant correlation between the contents of phenolics and flavonoids (Fig. 5b) as well as between RP versus phenolics' and flavonoids' contents (Fig. 6a); but such a correlation did not exist between phenolics and DPPH scavenging activity (Fig. 6b). Thus, it seems that the RP and the DPPH scavenging activity may have different mechanisms, since the former is dependent on the substrate phenolics but the latter is not. In agreement with our findings, Sulaiman et al. (2011) demonstrated significant correlation of the phenolics' content with ferric reducing antioxidant activity of the SSFS but not with the DPPH scavenging activity. Nevertheless, Babbar et al. (2011) demonstrated positive correlation between phenolics content, RP and DPPH scavenging activity of several plant residues in an SSFS. The pivotal role of phenolics in the antioxidant activity of SSFS has been documented by Rebello et al. (2014) who claimed that the high-phenolics' content of banana peel is responsible for its high antioxidant activity, which justifies the use of banana peel as a profitable source of bioactive phenolic compounds. The antioxidant activity of an SSFS employing rice seeds and Aspergillus spp. is related to the phenolics' content (Sadh et al. 2017). Likewise, the enhancement of DPPH scavenging activity of chokeberry (Aronia melanocarpa) pomace inoculated with various filamentous fungi including Aspergillus and Rhizopus spp. was associated with increasing levels of phenolics and flavonoids (Dulf et al. 2018). The greater DPPH scavenging activity and RP of chickpea upon inoculation with Cordyceps militaris had been related to the higher total phenolic and saponin contents of the SSFS (Xiao et al. 2014).

The variability in flavonoid content among the tested substrates, as well as the fungal action on the substrate flavonoids, was drastic compared with that in phenolic content. The highest flavonoid content in pomegranate peel was 30 -fold the minimum level of orange peel. In addition, the fungal action varied from consumption to the point of depletion to production up to several folds of the native flavonoid content. The flavonoid-consuming activity was most expressed by the two basidiomycetes on rice straw while the producing activity was 


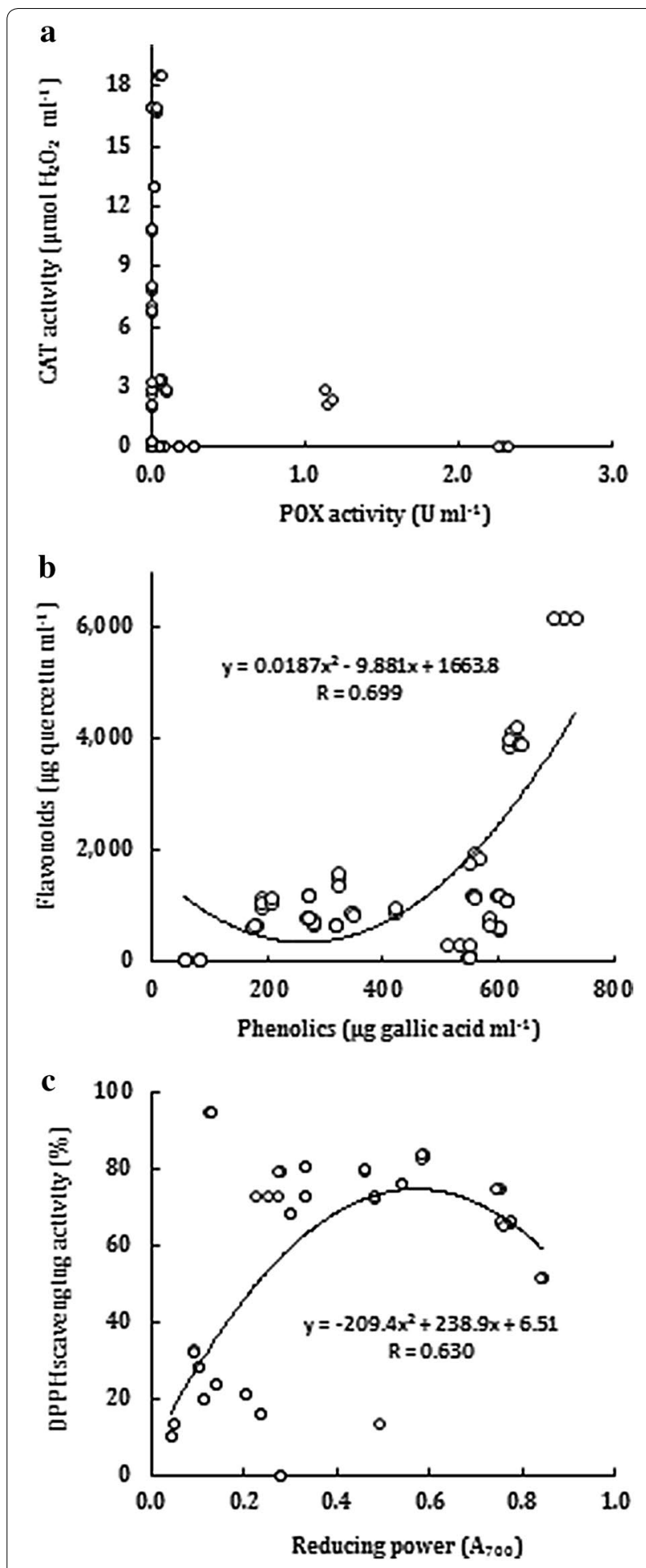

Fig. 5 Correlation of CAT versus POX (a), flavonoids versus phenolics (b) and DPPH scavenging activity versus RP (c) of an SSFS employing two basidiomycete fungi: P. columbinus and P. floridanus and two ascomycetes: As. fumigatus and P. variotii on peels of banana, pomegranate and orange, empty pods of pea and rice straw
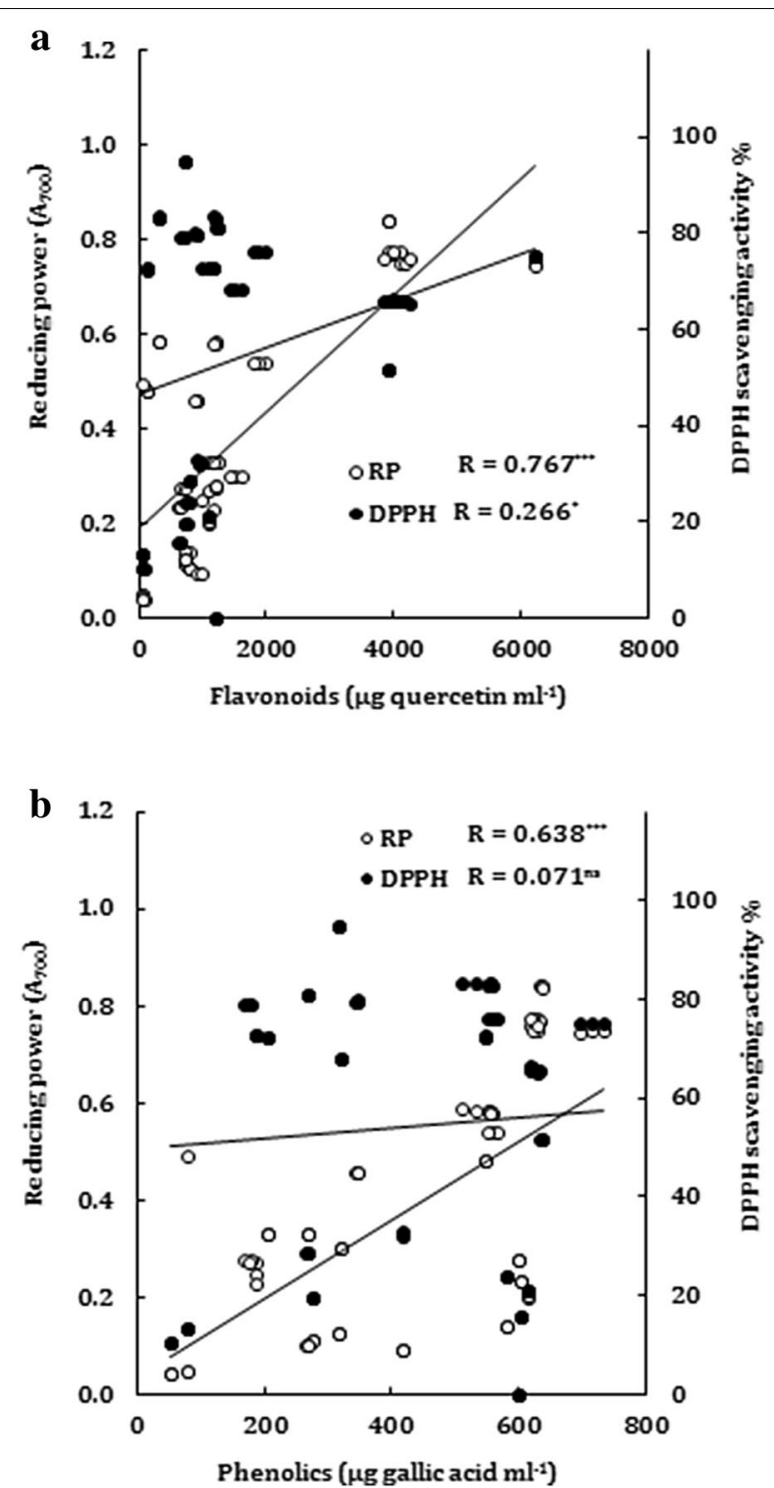

Fig. 6 Correlation of RP and DPPH scavenging activity versus flavonoids (a) and phenolics (b) of an SSFS employing two basidiomycete fungi: $P$. columbinus and $P$. floridanus and two ascomycetes: A. fumigatus and P. variotii on peels of banana, pomegranate and orange, empty pea pods and rice straw. The values of R with $\left(^{*}\right),\left(^{* *}\right)$ and (ns) refer to significant, very highly significant and non-significant correlation, respectively

most evident by the two ascomycetes on orange peel. Although the antioxidant activity, in terms of the DPPH scavenging activity and RP, of the extracts of four Pleurotus species (including P. columbinus) was attributed to the contents of phenolics and flavonoids (Irshad et al. 2017), the present work presented a different pattern. The higher positive linear correlation of reducing power and DPPH scavenging activity with flavonoid content of the SSFS than with the phenolic content (Fig. 6a, b) suggests 
greater participation of flavonoids than phenolics in the RP and DPPH scavenging activity of the SSF system.

The fungal effect on RP of the SSFS was generally limited and independent of the fungal taxonomic group, being negligible on pomegranate peel and mild on banana peel. The different ranks of the DPPH scavenging activity and RP among the tested substrates were tinged with a common pattern of higher activities of peels of pomegranate, banana and orange than those of rice straw and empty pea pods. This might signify that the two activities (the DPPH scavenging activity and RP) are performed partially via a common mechanism but with different details. The reducing power was highly significantly correlated with flavonoids $(R=0.767$, Fig. 6a) and phenolics $(R=0.638$, Fig. $6 \mathrm{~b})$, whereas the DPPH scavenging activity exhibited just significant correlation with flavonoids ( $R=0.266$, Fig. 6a) but was non-significantly correlated with phenolics (Fig. 6b). In addition, the present work suggests that the fungal effect on the RP and DPPH scavenging activity of the SSFS was more related to the substrate than to the fungal taxonomic group; since the fungal action was moderate on peels of pomegranate, banana and orange but marked on the empty pea pods and rice straw.

\section{Conclusions}

The present study demonstrated greater role of substrate than the fungal species in the antioxidant activity of the SSFS. Orange peel is the appropriate substrate for the production of fungal CAT and POX, banana peel is more suitable for CAT and pomegranate peel is suitable for the production of phenolics and flavonoids. The basidiomycete fungi possess higher POX activity compared with the ascomycetes, but the reverse was true for CAT. It seems that high POX activity is associated with low CAT activity and vice versa. The basidiomycete fungi have higher consuming ability of substrate phenolics and flavonoids than the ascomycetes. The RP of the SSFS rather than its $\mathrm{DPPH}$ scavenging activity is correlated to its phenolics and particularly flavonoids' contents.

\section{Abbreviations}

ANOVA: Analysis of variance; CAT: Catalase; 2,4-DCP: 2,4-dichlorophenol; DPPH: 2,2-diphenyl-1-picrylhydrazyl; PDA: Potato dextrose agar medium; POX: Peroxidase; SSFS: Solid state fermentation system.

\section{Acknowledgements}

Not applicable.

\section{Authors' contributions}

AAE and MMN provided and identified the fungal isolates. NGI conducted the experiments and performed biochemical analysis. TME and MMM performed statistical analysis and presented data in figures and tables. TME and MME wrote the draft of the manuscript. All authors read and approved the manuscript.
Funding

Not applicable.

\section{Availability of data and materials}

The datasets used and/or analyzed during the current study are available from the corresponding author on reasonable request.

\section{Ethics approval and consent to participate}

Not applicable.

\section{Consent for publication}

Not applicable.

\section{Competing interests}

The authors declare that they have no competing interests.

Received: 28 February 2020 Accepted: 11 May 2020

Published online: 16 May 2020

\section{References}

Abdelhady S, Borello D, Shaban A, Rispoli F (2014) Viability study of biomass power plant fired with rice straw in Egypt. Energy Procedia 61:211-215

Abou Hussein SD, Sawan OM (2010) The utilization of agricultural waste as one of the environmental issues in Egypt (a case study). J Appl Sci Res 6(8):1116-1124

Babbar N, Oberoi HS, Uppal DS, Patil RT (2011) Total phenolic content and antioxidant capacity of extracts obtained from six important fruit residues. Food Res Int 44(1):391-396

Bind A, Singh SK, Prakash V, Kumar M (2014) Evaluation of antioxidants through solid state fermentation from pomegranate peels using AspergilIus niger and its antibacterial properties. Int J Pharm Biol Sci 4:104-112

Biswas MK, Biswas SB (2015) Recycling of ligno-cellulosic waste materials through Oyster mushroom cultivation for sustainable food production. Ecoscan 9:655-659

Brar SK, Dhillon GS, Soccol CR (eds) (2013) Biotransformation of Waste Biomass into High Value Biochemicals. Springer Science and Business Media

Butkhup L, Samappito W, Jorjong S (2018) Evaluation of bioactivities and phenolic contents of wild edible mushrooms from northeastern Thailand. Food Sci Biotechnol 27(1):193-202

Carocho M, Morales P, Ferreira IC (2018) Antioxidants: reviewing the chemistry, food applications, legislation and role as preservatives. Trends Food Sci Technol 71:107-120

Dulf FV, Vodnar DC, Dulf EH, Diaconeasa Z, Socaciu C (2018) Liberation and recovery of phenolic antioxidants and lipids in chokeberry (Aronia melanocarpa) pomace by solid-state bioprocessing using Aspergillus niger and Rhizopus oligosporus strains. LWT Food Sci Technol 87:241-249

El-Katony TM, El-Dein MMN, El-Fallal AA, Ibrahim NG (2019) Effect of the taxonomic group of fungi and type of substrate on the antioxidant activity of a solid-state fermentation system. Int Microbiol 22:203-215

Hatano T, Kagawa H, Yasuhara T, Okuda T (1988) Two new flavonoids and other constituents in licorice root: their relative astringency and radical scavenging affects. Chem Pharm Bull 36:2090-2097

Inácio FD, Ferreira RO, De Araujo CAV, Peralta RM, De Souza CGM (2015) Production of enzymes and biotransformation of orange waste by Oyster mushroom, Pleurotus pulmonarius (Fr) Ouél. Adv Microbiol 5:1-8

Irshad A, Shahid M, Asghar M, Khan JA (2017) Antioxidant potential analysis of P. ostreatus, P. sajor-caju, P. sapidus and P. columbinus. J Biol Reg Home Ag 31(3):705-709

Luque-Rodríguez JM, de Castro ML, Pérez-Juan P (2007) Dynamic superheated liquid extraction of anthocyanins and other phenolics from red grape skins of winemaking residues. Bioresour Technol 98:2705-2713

Martinez-Avila GCG, Aguilera AF, Saucedo S, Rojas R, Rodriguez R, Aguilar CN (2014) Fruit wastes fermentation for phenolic antioxidants production and their application in manufacture of edible coatings and films. Crit Rev Food Sci Nutr 54:303-311

Mok WK, Tan YX, Lee J, Kim J, Chen WN (2019) A metabolomic approach to understand the solid-state fermentation of okara using Bacillus subtilis WX-17 for enhanced nutritional profile. AMB Express 9(1):60 
Oyaizu M (1986) Studies on products of browning reactions: antioxidative activities of products of browning reaction prepared from glucosamine. Jpn J Nutr 44:307-315

Ramachandra M, Crawford DL, Hertel G (1988) Characterization of an extracellular lignin peroxidase of the lignocellulolytic actinomycete Streptomyces viridosporus. Appl Environ Microbiol 54:3057-3063

Ranneh Y, Ali F, Akim AM, Hamid HA, Khazaai H, Fadel A (2017) Crosstalk between reactive oxygen species and pro-inflammatory markers in developing various chronic diseases: a review. Appl Biol Chem 60:327-338

Ravindran R, Jaiswal A (2016) Microbial enzyme production using lignocellulosic food industry wastes as feedstock: a review. Bioengineering 3(4):30

Rebello LPG, Ramos AM, Pertuzatti PB, Barcia MT, Castillo-Muñoz N, HermosínGutiérrez I (2014) Flour of banana (Musa AAA) peel as a source of antioxidant phenolic compounds. Food Res Int 55:397-403

Sadh PK, Saharan P, Surekha Duhan JS (2017) Bioaugmentation of phenolics and antioxidant activity of Oryza sativa by solid state fermentation using Aspergillus spp. Int Food Res J 24(3):1160-1166

Schmidt CG, Gonçalves LM, Prietto L, Hackbart HS, Furlong EB (2014) Antioxidant activity and enzyme inhibition of phenolic acids from fermented rice bran with fungus Rhizopus oryzae. Food Chem 146:371-377

Sharma R, Oberoi HS, Dhillon GS (2016) Fruit and vegetable processing waste: renewable feed stocks for enzyme production. In: Dhillon GS, Kaur S (eds) Agro-industrial wastes as feedstock for enzyme production. Academic Press, London, pp 23-59

Singh HB, Singh BN, Singh SP, Nautiyal CS (2010) Solid-state cultivation of Trichoderma harzianum NBRI-1055 for modulating natural antioxidants in soybean seed matrix. Bioresour Technol 101(16):6444-6453
Singh R, Srivastava M, Shukla A (2016) Environmental sustainability of bioethanol production from rice straw in India: a review. Renew Sustain Energy Rev 54:202-216

Souleman AM, Ibrahim GE (2016) Evaluation of Egyptian pomegranate cultivars for antioxidant activity, phenolic and flavonoid contents. Egypt Pharm J 15(3):143-149

Sulaiman SF, Yusoff NAM, Eldeen IM, Seow EM, Sajak AAB, Ooi KL (2011) Correlation between total phenolic and mineral contents with antioxidant activity of eight Malaysian bananas (Musa sp.). J Food Compos Anal 24(1):1-10

Teranishi Y, Tanaka A, Osumi M, Fukui S (1974) Catalase activities of hydrocarbon-utilizing Candida yeasts. Agric Biol Chem 389:1213-1220y

Vu HT, Scarlett CJ, Vuong QV (2018) Phenolic compounds within banana peel and their potential uses: a review. J Funct Foods 40:238-248

Wadhwa M, Bakshi MPS, Makkar HPS (2015) Wastes to worth: value added products from fruit and vegetable wastes. CAB International 43:1-25

Xiao Y, Xing G, Rui X, Li W, Chen X, Jiang M, Dong M (2014) Enhancement of the antioxidant capacity of chickpeas by solid state fermentation with Cordyceps militaris SN-18. J Funct Foods 10:210-222

Yang XM, Yu W, Ou ZP, Ma HL, Liu WM, Ji XL (2009) Antioxidant and immunity activity of water extract and crude polysaccharide from Ficus carica L. fruit. Plant Foods Hum Nutr 64:167-173

\section{Publisher's Note}

Springer Nature remains neutral with regard to jurisdictional claims in published maps and institutional affiliations.

\section{Submit your manuscript to a SpringerOpen ${ }^{\circ}$ journal and benefit from:}

- Convenient online submission

- Rigorous peer review

- Open access: articles freely available online

- High visibility within the field

- Retaining the copyright to your article

Submit your next manuscript at $\boldsymbol{\nabla}$ springeropen.com 